\title{
O Perigo Vermelho no cinema brasileiro: as narrativas de exilados e ex-presos políticos da ditadura militar no documentário contemporâneo
}

\section{RESUMO}

Na primeira década de 2000, o cinema brasileiro demonstrou um crescente interesse por retratar nas telas episódios da ditadura militar no país, remexendo em feridas, em assuntos complexos, dolorosos de nosso passado. O que para alguns militares soou como um revanchismo dos comunistas ou da esquerda brasileira que teriam invadido a mídia brasileira. Sendo assim, a partir da análise dos filmes Vlado, 30 anos depois (2005), Hércules 56 (2006) e Caparaó (2006) procuramos apontar algumas reflexões iniciais de como o documentário brasileiro contemporâneo, ao atualizar o passado da ditadura militar a partir de um compromisso ético e político com a memória daqueles que participaram da luta armada no país, trava uma batalha estética contra o esquecimento e a denegação de um período sombrio da recente história brasileira.

\section{PALAVRAS-CHAVE}

Documentário

Memória

Ditadura militar

The Red Danger in Brazilian cinema: the narratives of political exiled people and ex-prisoners of the military dictatorship in the contemporary documentary

\section{ABSTRACT}

In the first decade of 2000 the Brazilian cinema demonstrated a growing interest in portray in the screens episodes of the military dictatorship in the country, rummaging through hurts, complex and painful subject of our past. What for some military men was a revenge of the communists or of the Brazilian political left that would have invaded the Brazilian media. This way, starting from the analyzes of the Vlado, 30 years later (2005), Hércules 56 (2006) and Caparaó (2006) movies, we intended to point some initial reflections about how the contemporary Brazilian documentary, when update the past of the military dictatorship from a ethical and political compromise with the memory of the ones who participated of the armed fight in the country, struggle a esthetical fight against the forgetfulness and the denial of a dark period of the recent Brazilian history.

\section{KEYWORDS}

Documentary

Memory

Military dictatorship

\section{Cássio dos Santos Tomaim \\ Professor do Departamento de Ciências da Comunicação do CESNORS-UFSM/RS/BR \\ tomaim78@gmail.com}

Depois de mais de 40 anos do golpe militar brasileiro em 1964 podemos considerar que o cinema nacional definitivamente resolveu "tirar os roteiros das gavetas", antes escondidos da repressão e da censura. Desde 1997, data do lançamento de $O$ que é isso Companheiro? (Bruno Barreto), um dos primeiros filmes da fase de "retomada" do cinema brasileiro a explorar a memória daqueles anos de chumbo, somaram-se a nossa cinematografia mais de 10 longas-metragens que trouxeram para a grande tela diversos retratos da ditadura militar, da guerrilha, da repressão ou da tortura. Um conjunto significativo de produções, principalmente se levarmos em conta que somente três títulos quebraram o silêncio em pleno processo de redemocratização no país, são eles Pra Frente Brasil (Roberto Farias, 1982), O Bom Burguês (Osvaldo Caldeira, 1982) e Que Bom Te Ver Viva (Lúcia Murat, 1988). ${ }^{1}$

É evidente que foram poucos os cineastas brasileiros que se sentiram à vontade para fazer filmes sobre a ditadura militar quando ela agonizava ou quando o país dava os seus primeiros sinais de democracia. As feridas 
ainda estavam escancaradas dos dois lados, militares e a esquerda militante, ambos tiveram suas baixas morais e humanas, preferindo em muitos casos o silêncio. Os traumas de mais de 20 anos de repressão foram grandes e a ditadura militar tornou-se um tabu no Brasil nas décadas seguintes.

Tabu que alimentou o esquecimento, a denegação, mas que na primeira década de 2000 foi quebrado pelo cinema brasileiro que contou com uma produção destinada a revisitar a temática da ditadura militar. O que soou para alguns setores conservadores da sociedade, como as Forças Armadas, como uma atitude revanchista da esquerda brasileira.

Entre os longas-metragens estão sete ficções: CabraCega (Toni Venturi, 2005); Quase Dois Irmãos (Lucia Murat, 2005); Conspiração do Silêncio - Araguaia (Ronaldo Duque, 2006); Sonhos e Desejos (Marcelo Santiago, 2006); Zuzu Angel (Sérgio Rezende, 2006); O Ano em Que Meus Pais Sairam de Férias (Cao Hamburger, 2006) e Batismo de Sangue (Helvécio Ratton, 2006); e quatro documentários: Tempo de Resistência (André Ristum, 2003); Vlado, 30 anos depois (João Batista de Andrade, 2005); Caparaó (Flávio Frederico, 2006) e Hércules 56 (Silvio Da-Rin, 2006). Somam-se a estes, outros três documentários lançados no Brasil no final de 2009 e início de 2010, que merecem os méritos por abordarem assuntos até então pouco explorados pelo cinema brasileiro a respeito daqueles anos de chumbo. São eles: Simonal - Ninguém Sabe o Duro que Eu Dei (Cláudio Manoel, Micael Langer e Calvito Leal); ${ }^{2}$ Reparação (Daniel Moreno) ${ }^{3}$ e Cidadão Boilesen (Chaim Litewski). ${ }^{4}$

Assim, diante desta produção, vejo a necessidade de direcionarmos uma maior atenção ao cinema de não-ficção que, por suas particularidades estéticas, não só registram, mas também articulam as narrativas de exilados e ex-presos políticos, a fim de que possamos compreender como estes documentários assumem um dever de memória que não permite que as atrocidades da ditadura militar sejam esquecidas. Dever que para alguns militares tem sido sinônimo de um avanço comunista na mídia brasileira, que aproveita para realizar filmes marcados por um forte ressentimento de antimilitarismo oriundo do período autoritário.

\section{0 perigo vermelho na mídia brasileira}

Inspirados em certo caráter nacionalista, os militares sempre foram o grupo social mais receptivo às propostas anticomunistas no Brasil, segundo Motta
(2002). Embalados pelas matrizes do anticomunismo (o catolicismo, o nacionalismo e o liberalismo), os militares combatiam o "perigo vermelho" em defesa da Pátria. Esta aproximação dos militares ao sentimento anticomunista pode ser explicada pelas próprias características da instituição militar. Para o autor, primeiramente, nos meios militares já havia uma tendência natural em respeitar o status quo e refutar qualquer tentativa revolucionária ou de ruptura da ordem; e, como defensores da ordem, viam-se no dever de preservar a integridade nacional; por fim, devido ao forte respeito pela hierarquia militar, temia-se o que de fato uma revolução poderia provocar nas estruturas das Forças Armadas.

No entanto, segundo o autor, foi o levante comunista de 1935 que fortaleceu ainda mais o anticomunismo entre os militares, uma vez que adicionou uma tonalidade cinzenta ao imaginário anticomunista: os militares revolucionários que tomaram em armas naquele episódio foram acusados de traírem os seus pares e a instituição militar, além de acusados de terem assassinado alguns companheiros de farda enquanto dormiam. Logo, incorporava-se ao imaginário anticomunista o sabor da traição, seguida da covardia.

$\mathrm{E}$ os militares sempre fizeram questão de rememorar este episódio. A partir de 1936, a vitória sobre a Intentona Comunista entrou para o calendário cívico das Forças Armadas, sendo comemorada anualmente nos quartéis. Recordava-se, então, o dia da "traição" como uma forma de renovar os votos contra o comunismo, além de incorporar nas novas gerações de militares os valores do sentimento de anticomunismo.

Lição de casa que as Forças Armadas levam a sério até hoje. Se a esquerda, desde o início da redemocratização, quebrou o silêncio e expôs os horrores das torturas, coube aos militares a via contrária, dentro da caserna ainda se estimula a legitimação da tortura como um mecanismo eficaz do Estado contra a violência e o radicalismo.

Porém, é preciso dizer que, no contexto dos anos que se seguiram à abertura política no país, há quem acredite que tanto torturados quanto torturadores pagaram altos preços. De um lado ficaram as marcas, as cicatrizes físicas e psicológicas do combate, mas do outro cicatrizes que abalaram os princípios morais de uma instituição. Por fim, a ditadura foi responsável por definhar qualquer iniciativa de convivência entre os dois lados já que, nas palavras de um ex-militante da esquerda armada, o jornalista Flávio Tavares, "a tortura destruiu os torturados e aniquilou, também, os torturadores, ao 
transformá-los de combatentes militares em verdugos, tornando-lhes o mundo incompreensível" (apud Martins Filho, 2002, p. 199).

Desta forma, temos que o período de pós-ditadura refletiu a inabilidade do convívio entre a esquerda e os militares, deixando aflorar um outro sentimento: o antimilitarismo. Os primeiros anos que se seguiram ao fim do regime militar mostraram ser um terreno fértil para ressentimentos dos dois lados que protagonizaram a nossa história naquele período de "chumbo". E foram estes ressentimentos que moveram (e ainda movem) uma disputa pela “memória de 1964". Por sua vez, nestes novos enquadramentos o esquecimento não deixou de operar. Aliás, o esquecimento deveria ser a peça-chave do processo de Anistia, iniciado em 1979. É o que defendem os militares que insistem em afirmar que o contrato foi quebrado, que ao invés de um esquecimento mútuo como "solução da Anistia", o que ocorreu foi o contrário, temos a esquerda armada "vomitando o ódio da derrota" (Passarinho apud Martins Filho, 2002, p. 181).

Segundo Martins Filho (2002), enquanto os exmilitantes se esforçam para rememorar os acontecimentos de 1960/70, os militares claramente preferem que tudo seja esquecido dentro de uma política de reconciliação. Logo, entre os oficiais, ressalta o autor, é unânime a visão de que "uma vez derrotada, a esquerda esforçouse por vencer na batalha das letras, aquilo que perdeu no embate das armas" (Martins Filho, 2002, p. 180). A esta esquerda letrada o general Oswaldo Muniz Oliva denominou de "narradores de mão única", ao enfatizar que hoje predominam novelas e filmes "aparentemente históricos" que subvertem a verdade, transformando "todos os radicais violentos que pretendiam, pelas armas, implantar o comunismo (com dinheiro estrangeiro ou roubado) - padrão Fidel Castro - em nossa terra" em "heróicos defensores da democracia" (Oliva apud Martins Filho, 2002, p. 180).

$\mathrm{Na}$ verdade, os militares nutrem um sentimento de injustiça e dizem ter sido mal interpretados. Hoje fazem questão de relembrar da cumplicidade da sociedade civil, da Igreja, dos empresários e da classe média na "Revolução de 1964". É o que faz o general Leônidas Pires Gonçalves que ocupava, em 1974, a Chefia do Estado-Maior do I Exército e comandava o Centro de Operações de Defesa Interna (CODI). Em entrevista aos historiadores Maria Celina D’Araujo, Gláucio Ary Dillon Soares e Celso Castro ele afirma que
Tenho o hábito de repetir e, se não ouviram de alguém, vão ouvir pela primeira vez: acho que as Forças Armadas até hoje são ressentidas com a sociedade brasileira. Porque a sociedade brasileira nos levou, foi uma das responsáveis pela Revolução de 64, e hoje em dia a mídia não se cansa de nos jogar na cara que nós somos torturadores, que somos matadores, que somos isso, somos aquilo. [...]. Acho que há muita injustiça. (apud D'Araujo; Soares ; Castro, 1994, p. 127).

Mas a indignação do general encontra um alvo: a mídia, um "covil de comunistas". $\mathrm{Na}$ sua visão, "a esquerda invadiu muito a mídia e fica insistindo. Todo dia tem uma história, todo dia tem uma mentira, todo dia tem uma coisa. Isso nos deixou muito magoados". Sem negar que tenham ocorrido as torturas, os assassinatos, Leônidas Pires se irrita com as "mentiras" que a mídia constrói sobre o Exército, transformando injustamente, no seu entender, os militares em matadores, torturadores. O que para o general trata-se de uma safadeza histórica: "É uma safadeza histórica! [grifo dos autores] E se ensina isso nos colégios. Não sei quais são as concepções dos senhores. Se forem de esquerda, azar o seu" (apud D’Araujo; Soares; Castro, 1994, p. 128).

\section{O documentário como atividade de luto}

"Mentiras", "safadezas históricas", "retóricas de esquerda" ou "narrativas de mão única" são alguns dos adjetivos que os militares atribuem aos filmes que retratam os anos de repressão no Brasil. Mas é preciso que se diga, não há memória descompromissada com o passado. Logo, a "verdade do passado" é mais uma ética da ação presente, segundo Gagnebin (1998). Em outras palavras, a narração do passado sempre exige um alerta, pois é escrito no presente e para o presente, portanto, o documentarista é responsável por articular um passado sempre ameaçado pelos interesses do presente.

\section{Assim, os recentes filmes documentários que abordam a temática da ditadura militar acabam assumindo um caráfer de resistência, travando uma}




\section{Iuta contra o esquecimento e a denegação que muito fem a ver com a consciência política e da ética do olhar de seus realizadores.}

O que nos leva a acreditar que o documentário, ao permitir ao outro rememorar ou reler o seu passado, os seus traumas, as suas experiências, seja uma arte potencialmente crítica e reveladora (no sentido de salvação de significados ocultos, em termos benjaminianos). Por isso, o nosso interesse em compreender como as narrativas dos exilados e ex-presos políticos são articuladas em filmes como Vlado, 30 anos depois, Caparaó e Hércules 56 e atualizam certas imagens do passado da ditadura militar. ${ }^{5}$

A respeito destes filmes vale questionarmos não o quanto os testemunhos são verdadeiros, mas o quanto o encontro do cineasta com os personagens sociais esteve delimitado por uma ação política do presente para com um passado ameaçado, pois "a preocupação com a verdade do passado se completa na exigência de um presente que, também, possa ser verdadeiro" (Gagnebin, 1998, p. 221).

Dentre os documentários aqui selecionados, Vlado, 30 anos depois é o filme que melhor representa este compromisso que o cineasta assume diante do presente ao embrenhar-se em busca dos rastros do passado, tarefa difícil principalmente quando este exercício de rememorar esbarra em lembranças inenarráveis, impossíveis de serem traduzidas em palavras pelos personagens sociais, restando ao filme apenas o peso do silêncio.

Em seu filme-tributo ao amigo Vladimir Herzog, jornalista assassinado nos porões da ditadura militar, João Batista de Andrade reconhece diante de nós espectadores o seu dever de memória e nos oferece imagens afetivas daqueles anos de chumbo. Mas a prova de que o filme é um diálogo com o presente vem já nas primeiras sequências quando, de microfone em punho, o cineasta aparece abordando e entrevistando os passantes na praça da Catedral da Sé, um lugar de memória daquela época; igreja onde o corpo de Herzog foi velado e ponto de partida da retomada da luta democrática no país naquele ano de 1975.

O cineasta segue registrando as rápidas declarações das pessoas que se sentem constrangidas e incomodadas diante da pergunta: "O que você sabe deste nome, Vladimir Herzog?” Por puro desconhecimento, jovens e adultos, em um tradicional "povo fala" - herança que João Batista de Andrade trouxe da época de suas experiências no jornalismo televisivo, em especial na TV Cultura, onde trabalhou com Vlado - surgem na grande tela do cinema como imagens e sons que atestam o porquê de fazer um filme sobre Vladimir Herzog e a ditadura militar. Artifício audiovisual que reforça a necessidade do trabalho de luto executado pelo documentarista. As respostas das pessoas são as mais variadas; em geral, desconhecem, outras arriscam, mas o clichê permanece na tela como desculpa: "Nesta época eu não era nem nascido ainda". O fato de não terem vivenciado aqueles anos serve para muitas pessoas como desculpa para o esquecimento; não se preocupam a ponto de arriscarem um tímido elogio: "Conheço muito pouco, eu não sou da época. Mas, sei lá, acho que deveria voltar [a ditadura]." Assim, este recurso do "povo fala" foi uma estratégia do cineasta para ratificar diante do espectador o quanto o povo brasileiro desconhece alguns episódios de sua história recente, o quanto o esquecimento já operou na construção do nosso passado.

Mas a maior contribuição de Vlado... para a luta contra a denegação dos horrores dos porões do DOICODI foi a forma como trabalhou os depoimentos de seus personagens sociais, muitos deles amigos íntimos do cineasta e que na época tinham algum tipo de relacionamento, pessoal ou profissional, com Herzog. Amizade que proporcionou ao documentário depoimentos em tom de desabafo, sem o constrangimento de revelar-se a um estranho. A presença-câmera de João Batista de Andrade no filme vem reforçar um apelo performático, de que o documentarista é um deles, de que aquele encontro é um acontecimento íntimo do qual lhe coube a tarefa de guardião da memória de sua geração.

Para o registro destes depoimentos o cineasta fez uma escolha estética por filmar com uma pequena câmera na mão, enquanto conversava com os entrevistados. $\mathrm{O}$ resultado são big-closes dos atores sociais do filme que dominam a tela e que, apesar de às vezes trêmulos, sem foco ou distorcidos cumprem a sua função, registram o inenarrável, o que não pode ser traduzido em palavras, o que não pode ser atingido cognitivamente. É escamoteada entre os silêncios e os tropeços dos depoimentos, nas rugas das faces, no incômodo e mal-estar dos narradores que se faz presente diante da matéria-prima da memória: 
as dimensões afetivas das vidas dos narradores em contato com o mundo vivido.

Desta forma, os depoimentos sobre as prisões e as torturas são reveladores no sentido de que o documentário consegue sutilmente trazer à tona sentimentos e ressentimentos antes reservados à memória (involuntária) destes entrevistados, lembranças dolorosas de tempos de humilhação, de impotência, de ódio. Enquanto os vestígios documentais sobre a ditadura militar são apagados ou silenciados por leis, o filme Vlado... vasculha as inscrições afetivas da memória que, aliás, são duradouras. Como podemos perceber pelo depoimento do jornalista Frederico Pessoa, que nos ensina o quanto o sentimento de humilhação torna-se uma experiência insuperável e vivida de forma obsessiva:

Você ser fisicamente destruído. E tem certo momento que você se sente literalmente desmontar, quando te aplicam choque no ouvido, na boca ou no ânus. Você se sente como estivesse desmoronando, entendeu? E esta sensação de acompanha pro resto da vida [...] Quer dizer [...] Que você vai desmanchando por dentro. Tem momentos [...] Quer dizer [...] Que o sofrimento de outras pessoas [...] Quer dizer [...] Chega a ser muito mais forte que o seu próprio sofrimento. Então, quando você vê um amigo, um companheiro, uma pessoa sendo torturada na tua frente, isso [...] No meu caso, a minha mulher [...] [neste instante temos o maior silêncio do filme, o entrevistado abaixa a cabeça e se cala diante da câmera, parece uma eternidade na película. A câmera continua firme no mesmo plano, espera que o narrador se recomponha diante do passado para que conclua]: Isto te marca pro resto da vida.

É verdade que em Vlado... também nos deparamos com uma enxurrada de depoimentos, o que em boa parte dos documentários não passa de uma muleta, um facilitador para a narrativa fílmica deste gênero. O que não é o caso, pois a escolha estética pelo bigclose potencializou os relatos de dor e humilhação; na tela tomam forma de grandes figuras que gritam, que se revoltam diante da câmera - alegorias da resistência. E, em certa medida, João Batista de Andrade valorizou o encontro, bem ao estilo do cinema-verdade, assumindo para o seu filme as subjetividades inerentes tanto ao realizador quanto aos personagens sociais. Enfim, em documentários como Vlado... testemunhamos o encontro daquele que opera uma câmera e a outra pessoa que não a tem.

Já em Caparaó, Flávio Frederico não consegue escapar das entrevistas, fazendo uma montagem pouco criativa, presa a sucessão de depoimentos, ora intercalando-os com imagens de arquivo. Um documentário expositivo dividido em três atos: "Os Sargentos"; "Os Marinheiros" e "Brizola". Nas duas primeiras seguem as apresentações dos personagens que irão ajudar o cineasta a contar a história do primeiro foco de resistência no país à ditadura militar, orquestrado por ex-sargentos do Exército e da Marinha expulsos das Forças Armadas durante a "Operação Limpeza" que os generais lideraram nos quartéis após o golpe de 1964. Já a terceira reúne alguns depoimentos e imagens de arquivo para narrar a relação de Leonel Brizola com os ex-militares, que foram buscar apoio político e financeiro no exgovernador do Rio Grande do Sul exilado no Uruguai. $\mathrm{E}$ mais adiante a montagem recorre a outros títulos para orientar o espectador no emaranhado de depoimentos dos vários personagens: "O caso das mãos amarradas" - episódio em que um guerrilheiro é morto durante um interrogatório -; "Primeira tentativa de guerrilha rural: Criciúma"; "Segunda tentativa da guerrilha rural: Serra do Caparaó"; "As armas" - em que os personagens contam que usaram ônibus comercial, trens e até uma Kombi da Kelloggs para transportar uma grande quantidade de munição e armamentos para a região escolhida para o movimento de resistência.

O filme recorre a algumas cenas ficcionais, principalmente para reconstituir o avanço dos guerrilheiros pela Serra do Caparaó (MG). No entanto, este recurso não é muito explorado no documentário, funciona como pequenos inserts para ilustrar os depoimentos dos personagens e ajudar no ritmo da narrativa, mas não se constitui como um elemento imprescindível ao filme. É descartável.

Entretanto, há dois trechos que destoam de todo o filme, quebrando a linha narrativa sustentada pela sucessiva intercalação de depoimentos em planos médios e closes. O primeiro é quando a câmera de Caparaó registra o cineasta acompanhando os ex-guerrilheiros por uma trilha na serra em busca de um lugar onde ainda estariam guardadas armas daquela época da resistência. No entanto, justapostas a estas imagens, não se deixa de intercalar depoimentos dos personagens sobre 
alguns episódios iniciais da estruturação da guerrilha. É nesta circunstância que temos uma primeira e rápida aparição do cineasta no documentário acompanhando uma conversa de um dos personagens, o ex-sargento do Exército Amadeu Felipe da Luz Ferreira, com um dos moradores local que lhe explica que a trilha que procuravam não existe mais. A câmera registra a cara de frustração do ex-comandante da guerrilha, que deve ter sido a mesma do documentarista, pois a única circunstância criada para o filme que escapava do mero registro das narrativas dos personagens encerra-se com uma sequência de imagens da serra coberta por um nevoeiro - como uma justificativa para o fracasso da tomada - e um depoimento de Ferreira sobre o desafio físico e mental dos guerrilheiros aos permanecerem naquele local, muitas vezes sem suprimentos.

O outro trecho é daqueles momentos que escapam do controle do documentarista enquanto realiza suas entrevistas, mas que em Caparaó servirá como recurso favorável para romper com sua narrativa engessada nos depoimentos diretos concedidos pelos personagens ao cineasta. É que pela primeira vez no filme a relação entrevistado/cineasta é suprimida pela valorização do diálogo entre dois personagens. $\mathrm{Na}$ tomada aparece o ex-subtenente paraquedista do Exército, Jelci Rodrigues Corrêa, que ao explicar como ocorreu a prisão do dos guerrilheiros dá uma "apimentada" no episódio, sugerindo que teria havido uma negociação para que a Polícia Militar mineira invadisse o acampamento sem fazer mortos e feridos. O que espanta o ex-marinheiro, Amaranto Rodrigues Moreira, que acompanha o seu depoimento, interrompendo-lhe e à filmagem para questionar se ele teria prova do que dizia, pois pela primeira vez ouvia esta versão. $\mathrm{Na}$ ocasião, o cineasta não interrompe o registro daquela tomada, que afinal é a única que consegue capturar uma imagem com uma intensidade diferente das demais. Mas rapidamente a montagem apela para o depoimento, ao sentir a necessidade de contrapor a versão, bem ao estilo jornalístico, e o cineasta ouve o comandante da guerrilha que nos explica que na ocasião o movimento já estava derrotado politicamente, mas que não houve nenhuma negociação. E o documentário retoma seu ritmo.

Desta forma, nota-se que o documentário ao ficar preso aos depoimentos acaba por incorporá-los, assumindo as memórias daqueles ex-guerrilheiros que em 1966 eram jovens sargentos. Ao final, o filme ratifica o depoimento de um dos personagens que acredita que Caparaó teria sido um gesto de rebeldia daqueles jovens militares, alimentados pela internacionalização de um espírito revolucionário presente na juventude daquela década de 1960. A última sequência surge como um elogio a toda uma geração que não só presenciou, mas também participou das transformações políticas e culturais do seu país, espelhados em tantos outros jovens pelo mundo que romperam com regras e tabus em nome da liberdade. Trata-se de um "videoclipe" de imagens de jovens em atos de protestos e rebeldias, que acompanhado da canção Marginália II, composta por Gilberto Gil e Torquato Neto, busca atualizar a euforia estética, cultural e política daquela época.

De certa medida, Hércules 56, de Silvio Da-Rin, também é uma homenagem à geração dos anos 1960/70, mas de uma perspectiva mais dialética do que naturalista, como presenciamos em Caparaó. O elogio está em compreender o contraditório da luta armada em que muitos jovens brasileiros se envolveram naqueles anos, incorporados sim de um espírito revolucionário, transformador, mas que não escaparam de cometer equívocos, como o seqüestro do embaixador norteamericano Charles Burke Elbrick, em 1969, depois trocado por 15 presos políticos. Equívoco assumido por muitos dos personagens deste filme, como o jornalista Flávio Tavares que na época foi um dos presos políticos que se beneficiaram daquela ação da esquerda brasileira. Sem dúvida um golpe duro nos militares, mas que logo responderam intensificando a repressão que, por sua vez, chegou a uma escala de truculência e crueldade inimagináveis.

Para ajudar a narrar esta história, Silvio Da-Rin recorre a alguns recursos. Já na primeira sequência somos apresentados a dois deles. A iconografia da ditadura militar brasileira é somada a uma narração em off do conteúdo do Manifesto do Sequestro, publicado nos jornais e lido nas TVs e Rádios da época. O narrador impõe um sentido dramático ao episódio retratado no manifesto. Assim, o uso que se faz do material de arquivo ganha um contorno diferente, ao invés de servirem como ilustração ou complemento as imagens são autônomas, potencializam a narrativa. Não há uma narração em off conduzindo-as, explicando-as. E nem mesmo mais adiante as sonoras dos depoimentos exercem este papel, muito comum em Caparaó.

A este recurso, soma-se um outro. A câmera percorre um corredor estreito, escuro [dando ao espectador um certo tom de que entramos em um ambiente sombrio], que nos leva ao interior de um bar onde encontramos em uma mesa cinco dos ex-militantes que participaram 
da ação do seqüestro do embaixador norte-americano. São eles: Claudio Torres, Daniel Airão Reis, Franklin Martins, Manoel Cyrillo e Paulo Tarso Venceslau. Nesta primeira aparição, estes personagens discutem um aspecto semântico, o de que a ação não poderia ser classificada como seqüestro, como fez os órgãos de repressão, mas sim como captura, já que se tratava de uma ação revolucionária e não de um crime.

Para registrar este reencontro dos ex-militantes, o cineasta recorre a mais de uma câmera e procura na montagem intercalar vários planos diferentes na tentativa de não perder a dinâmica daquela circunstância criada para o documentário, a de uma reunião de homens que aceitaram o convite para rememorar um fragmento de um episódio que marcou a resistência armada ao regime militar no Brasil.

Mas o filme não se apóia somente neste reencontro, também vai ouvir os relatos daqueles 15 presos políticos trocados pela vida do embaixador. Neste instante a histórica fotografia dos presos anistiados prontos para o embarque no avião Hércules da Força Aérea Brasileira, e outras imagens da época, passam a ser recursos importantes para o exercício de rememoração a qual o documentário convoca seus personagens. Vemos Da-Rin mostrando alguns vídeos e imagens aos ex-militantes, cenas que celebram no início do documentário o encontro entre o cineasta e seus personagens sociais. Como alguns dos ex-presos políticos já haviam falecido na época da realização do documentário, o cineasta buscou nos arquivos os depoimentos que estes concederam em outras ocasiões.

Sobre estes personagens, ao apresentá-los o cineasta não dispensa a informação de que quando presos pelos órgãos da repressão a maioria era jovens militantes de movimentos estudantis e operários, o que agrega um ingrediente para a luta armada no país: a imaturidade. Um elemento que mais tarde nos auxilia na compreensão do episódio do seqüestro e no modo como, hoje, aqueles senhores e aquela senhora - Maria Augusta Carneiro Ribeiro foi a única mulher incluída na lista dos presos políticos a serem libertados - relêem o passado sob um olhar dialético. Nas últimas sequências do filme, muitos destes personagens revelam que havia grandes divergências ideológicas entre eles, uma explicação plausível para a vitória da repressão sobre a esquerda armada brasileira, como nos expõe Mário Roberto Zanconato:

De repente sai um dos militares que estava torturando um grupo [...] e vai para cima de mim sem ter nada a haver com o meu interrogatório, mas parece que sabia quem eu era. Pegou a minha cabeça pelas duas orelhas [neste instante o personagem reproduz o gesto diante da câmera] e me sacudia: "Ô, seu filho da puta. Vocês acham que assim vocês vão conseguir ganhar da gente. Estes caras que nós pegamos aí são da ala vermelha do PCB. É a trigésima segunda organização que a gente desbarata. Vocês acham que assim divididos vão conseguir vencer a gente. Isso foi talvez [...] de cinco meses de prisão a imagem que mais me impactou. $\mathrm{O}$ Filho da Mãe tinha razão.

Nas palavras de alguns ex-guerilheiros, bastava reunilos para que estas contradições viessem à tona. E foi o que fez Silvio Da-Rin ao convocar para uma mesa de bar cinco dos ex-militantes que atuaram no seqüestro do embaixador. A circunstância do reencontro destes personagens favoreceu o registro das contradições e inúmeras versões de como se deu o seqüestro do embaixador, uma vez que estes integraram na época grupos diferentes da luta armada. As tomadas destas discussões no bar são enriquecedoras, revelam como não havia uma unidade na esquerda brasileira, como na cena em que debatem sobre a autoria do seqüestro.

\section{Considerações finais}

A tomada é o recorte que o diretor faz do mundo, mas que nasce de uma circunstância que se destaca pela presença da câmera e daquele que a manuseia, enquanto autoridade do discurso. Para Ramos (2005), a intensidade da tomada é um dos principais traços diferenciais da tradição documentária, e ela se configura a partir da idéia de que está explícito ao espectador do filme de nãoficção a presença da câmera e do sujeito que a sustenta no ato do registro, por mais ausentes que eles tentem transparecer no filme. É a experiência do espectador com este jogo duplo da imagem documental, presença/ ausência, ou seja, são as marcas deixadas pelo sujeitoda-câmera nas circunstâncias da tomada que aproxima o espectador de uma força viva: a intensidade do mundo vivido (Ramos, 2005, p. 167).

Neste sentido, 
uma análise de filmes como Vlado..., Caparaó e Hércules 56 vem nos ensinando que quando 0 assunto é um passado marcado por traumas, humilhações, como a difadura militar brasileira, nada mais apropriado do que um documentário que se caracteriza por descobrir 0 mundo por meio do encontro com o outro, em vez de um cinema sobre o outro, pois é desta maneira que temos chances de nos depararmos com as dimensões afetivas do passado.

Enquanto Caparaó aprisiona-se nos depoimentos, como um reduto de uma verdade do passado, a ponto de subordiná-los à lógica da narrativa fílmica, assim como faz com as imagens de arquivo, assumindo apenas o sentido de uma evidência para a argumentação do cineasta, em Vlado... os relatos ganham uma densidade por serem produtos de um encontro íntimo; João Batista de Andrade "atua" no filme, é mais um personagem e assume ao espectador a relação próxima que tem com o tema, com o personagem retratado e com as pessoas que o recebe em ambientes familiares. E, por fim, Hércules 56 não conta com este nível de intimidade com seus personagens, mas ao provocar um encontro entre eles, depois de mais de 30 anos do episódio, demonstra que o documentário ao assumir uma vontade de memória, no sentido de vigilância do presente, pode ser mais verdadeiro com o passado quando reconhece que "A memória é um fenômeno sempre atual, um elo vivido no eterno presente; a história, uma representação do passado" (Nora, 1993, p. 09).
Entre as diversas dispufas por uma memória da difadura militar, seja por exguerrilheiros ou militares, forfurados ou torfuradores, vítimas ou algozes, 0 cinema documentário brasileiro tem demonstrado o quanto é uma arte potencialmente crítica e reveladora, e que aos poucos vamos aprendendo a lição de Benjamin (1985, p. 204) a respeito do narrador: quanto maior for a nafuralidade com que os depoimentos dos afores sociais aconfecem diante da câmera, mais facilmente a sua história será incorporada à experiência do espectador que, dificilmente, irá resistir a recontá-la.

\section{NOTAS}

\footnotetext{
${ }^{1}$ Não que não tenham sido produzidos outros filmes durante os anos de chumbo que abordassem as temáticas decorrentes daquela traumática experiência política na qual o Brasil estava vivendo. Entretanto, como sabemos, devido à forte atuação dos órgãos de repressão e censura muitos filmes foram mutilados, outros apreendidos ainda em sua fase embrionária, além daqueles que chegaram a ser concluídos, mas jamais alcançaram a exibição nas grandes telas do país. É o caso do filme documentário Você Também Dá um Presunto Legal (1971) que Sérgio Muniz produziu na clandestinidade, mas foi aconselhado por amigos a não exibi-lo na época. $O$ filme
} 
apresenta a tese de que o Esquadrão da Morte, chefiado em São Paulo pelo delegado Sério Paranhos Fleury, foi a verdadeira "escola" da repressão política dos militares, intensificada naqueles anos de 1970.

2 Simonal - Ninguém Sabe o Duro que Eu Dei aborda os episódios nebulosos que envolveram a carreira musical de Wilson Simonal, encerrada bruscamente quando o cantor foi acusado de "dedo duro" da repressão.

3 A partir de um retrato da vida do piloto Orlando Lovecchio Filho, uma vítima das ações da luta armada no Brasil, que teve parte da perna esquerda amputada durante uma explosão na Biblioteca do Consulado dos Estados Unidos em março de 1968, no auge do regime militar, o filme Reparação questiona a política de indenização aos anistiados. Enquanto que algumas pessoas receberam reparações milionárias do Estado por terem sido fichadas nos órgãos de repressão do regime militar, Lovecchio Filho sobrevive com uma pensão do INSS, conquistada somente em 2004.

${ }^{4}$ Cidadão Boilesen é outro recente documentário que promete incomodar ao retratar a vida do empresário dinamarquês, naturalizado brasileiro, Henning Boilesen, que financiou abertamente a Oban (Operação Bandeirante), um dos principais centros de informações, investigações e torturas do regime militar. Anticomunista, Boilesen tinha um caráter sádico, adorava acompanhar as sessões de torturas, a ponto de emprestar carros da Ultragaz, empresa que presidia, para as operações militares da repressão. Em 2009, Cidadão Boilesen foi considerado o Melhor Filme Documentário no Festival É Tudo Verdade.
${ }^{5} \mathrm{O}$ documentário Tempo de Resistência, de André Ristum, não foi analisado para este trabalho, devido o pesquisador não ter tido acesso ao mesmo. Mas o filme merece uma reflexão a posterior dentro da perspectiva aqui adotada.

\section{REFERÊNCIAS}

BENJAMIN, Walter. Obras escolhidas I. Magia e técnica, arte e política. v.1. São Paulo: Brasiliense, 1985.

D'ARAUJO, Maria Celina; SOARES, Gláucio Ary Dillon; CASTRO, Celso (Orgs.). Visões do golpe: a memória militar sobre 1964. Rio de Janeiro: Relume-Dumará, 1994.

GAGNEBIN, Jeanne Marie. Verdade e memória do passado. Projeto História, São Paulo, v.17, p. 213-221, 1998.

MARTINS FILHO, João Roberto. A guerra da memória: a ditadura militar nos depoimentos de militantes e militares. Varia História, Belo Horizonte, n. 28, p. 178199, dez. 2002.

MOTTA, Rodrigo Patto Sá. Em guarda contra o perigo vermelho: o anticomunismo no Brasil (1917-1964). São Paulo: Perspectiva, 2002.

NORA, Pierre. Entre memória e história: a problemática dos lugares. Projeto História, São Paulo, n.10, p. 7-29, dez. 1993.

RAMOS, Fernão. Teoria Contemporânea do Cinema: Documentário e Narratividade Ficcional. vol. 2. São Paulo: Senac, 2005. 